\title{
O ACASO, A INCERTEZA E A DIFÍCIL RUPTURA COM O DETERMINISMO NA MATEMÁTICA DOS ANOS INICIAIS
}

\author{
José Maria Soares Rodrigues \\ (1Dhttps://orcid.org/0000-0002-1344-4239
}

Maria Tereza Carneiro Soares

(Dhttps://orcid.org/0000-0003-4645-8124

Resumo: Este texto tem como objetivo apresentar resultados de estudo teórico sobre as justificativas, objetivos e finalidades da inclusão de noções de probabilidade e estatística nos currículos escolares desde os Anos Iniciais, escritas em proposições curriculares anteriores à Base Nacional Comum Curricular, recentemente aprovada. Parte do pressuposto de ser necessária, mas difícil a tarefa de implementar tais noções na matemática escolar, particularmente nos Anos Iniciais. Foi elaborado com base em textos oriundos da produção científica resultante da pesquisa em Educação Matemática, Psicologia da Educação Matemática e Educação Estatística que trata do ensino de noções de probabilidade e estatística nos Anos Iniciais do Ensino Fundamental. Literatura acessada no período entre 2010 a 2018 e disponível em bancos de teses e dissertações; no site da Sociedade Brasileira de Educação Matemática; em bibliotecas virtuais; sites de periódicos; revistas para o professor e textos consultados diretamente na internet. Os argumentos encontrados nos levaram a resultados que reforçam a relevância da probabilidade e estatística, desde o início da escolaridade, para a compreensão dos fenômenos da sociedade contemporânea. Também trazem à luz aspectos e dificuldades que estão na antessala do documento curricular vigente, no que se refere à proposição da unidade temática denominada Probabilidade e Estatística.

Palavras-chave: Educação matemática. Matemática escolar. Ensino fundamental I. Noções de probabilidade e estatística. Incerteza.

1 Professor Associado da Universidade Federal do Pará, doutorado em Educação pela Universidade Federal do Paraná, linha de pesquisa Educação Matemática. E-mail:jmsr@ufpa.br

2Professora Associada da Universidade Federal do Paraná, doutorado em Educação pela Universidade de São Paulo.E-mail:mtcsoares@ufpr.br 


\section{CHANCE, UNCERTAINTY AND THE DIFFICULT BREAK WITH DETERMINISM IN THE EARLY YEARS OF SCHOOL MATHEMATICS}

Abstract: This text aims to present the results of a theoretical study on the justifications, objectives and purposes of including Probability and Statistics notions in school curricula since the early years, written in the curriculum proposals prior to the recently approved Curriculum Common National Base. It intends to underline the necessary, but difficult task of implementing such notions in school mathematics, particularly in the early years. It was elaborated based on texts from scientific production resulting from research in Mathematics Education, Psychology of Mathematics Education and Statistical Education that deals with the teaching of Probability and Statistics notions in the elementary school. Literature available in thesis and dissertations, on the Brazilian Society of Mathematics Education - SBEM website (for consultation of the annals of events and some books and periodicals available), in virtual libraries, journal sites, magazines for the teacher and texts consulted directly on the internet. The results reinforce the relevance of Probability and Statistics studies since the beginning of schooling, for understanding the phenomena of contemporary society and brings light to the aspects and difficulties that antedate the thematic unit called Probability and Statistics in the curriculum national base.

Keywords: Mathematics education. School mathematics. Elementary school.

Probability and statistics notions. Uncertainty.

\section{OPORTUNIDAD, INCERTIDUMBRE Y LA DIFÍCIL ROMPA CON EL DETERMINISMO EN LAS MATEMÁTICAS DE LOS PRIMEROS AÑOS}

Resumen: Este texto tiene como objetivo presentar los resultados de un estudio teórico sobre las justificaciones, objetivos y propósitos de incluir nociones de probabilidad y estadística en los planes de estudio escolares desde los primeros años, en las propuestas curriculares anteriores a la Base Nacional Comum Curricular. Tiene la intención de señalar la tarea necesaria pero difícil de implementar tales notiones en las matemáticas escolares, particularmente en los primeros años. Fue elaborado en base a textos de producción científica resultante de la investigación en Educación Matemática, Psicología de la Educación Matemática y Educación Estadística que se ocupa de la enseñanza de las nociones de probabilidad y estadística en los primeros años de la escuela primaria. Literatura disponible en tesis y disertaciones, en el sitio web de la Sociedad Brasileña de Educación Matemática, en bibliotecas virtuales, sitios web periódicos y revistas para el maestro. Los resultados resaltan la relevancia de estudios de Probabilidad y Estadística desde el comienzo de la escolarización para comprender los fenómenos de la sociedad contemporánea y sacan a la luz los aspectos que se encuentran en el primer plano de la base curricular actual con respecto a la propuesta de la unidad temática llamada Probabilidad y Estadística.

Palabras clave: Educación matemática. Matemáticas escolares. Escuela primaria. Nociones de probabilidad y estadística. Incertidumbre. 


\section{Introdução}

Desde as últimas décadas do século XX, noções de probabilidade e de estatística têm integrado propostas curriculares para o ensino de matemática em vários países (LOPES, 1998). No Brasil, a partir do final dos anos 1980, já era possível encontrar alguns indícios de uma tímida introdução desses temas (por exemplo, representações de possibilidades em problemas de contagens por meio de diagramas de árvores e leitura/representação de dados em tabelas e gráficos) nos currículos de algumas redes estaduais, municipais e privadas de ensino (o de São Paulo, é um dos exemplos), e em iniciativas dispersas de formação inicial e continuada de professores.

Mais recentemente, as justificativas para a inclusão desses temas foram sendo cada vez mais ampliadas, tanto nos currículos internacionais de matemática (de países como Estados Unidos, Japão, Alemanha, Espanha, Austrália, Áustria e tantos outros nos diferentes continentes) como nos desdobramentos das diretrizes curriculares brasileiras para o Ensino Fundamental de 9 (nove) anos (BRASIL, 2010), especificamente na área de Matemática (BRASIL, 2017), sempre calcadas no argumento de que estudos de probabilidade e estatística são necessários para que as pessoas possam compreender e lidar com situações que ocorrem cotidianamente e que se encontram no âmbito do acaso e da incerteza. São situações de risco, jogos de azar, questões climáticas, questões ambientais, questões econômicas, resultados de exames médicos, dentre outras. (BOROVCNIK, 2017; GODINO; BATANERO; CAÑIZARES, 1996; LOPES, 1998; OECD, 2013; PEREIRA-MENDOZA; SWIFT, 1981; RODRIGUES, 2011) entre outros.

Batanero et al. (2016) atestam que a intenção de se promover estudos desses conteúdos na escola têm como finalidade o desenvolvimento de um tipo de raciocínio não determinístico pelos estudantes, necessário para se compreender e transitar na sociedade contemporânea. Afirmam que os cidadãos precisam ir além de seus raciocínios determinísticos e aceitar a existência de acaso e não explicar tudo pela sorte ou destino, para que possam atuar adequadamente em sociedade, pois as pessoas precisam construir estratégias e modos para conduzir suas ações, de forma que possam ajudá-las na tomada de decisões no dia-a-dia e nas profissões que demandam um tipo de raciocínio não determinístico. 
$\mathrm{Na}$ Base Nacional Comum Curricular (BNCC) brasileira para o Ensino Fundamental, aprovada pelo Conselho Nacional de Educação (CNE) em 2017, probabilidade e estatística é a denominação de uma unidade temática em que a incerteza e o tratamento de dados são estudados. De acordo com o documento oficial, essa unidade temática "propõe a abordagem de conceitos, fatos e procedimentos presentes em muitas situações-problema da vida cotidiana, das ciências e da tecnologia" (BRASIL, 2017, p. 272).

Os primeiros resultados de pesquisa brasileira sobre a relevância da inserção da probabilidade e estatística na educação matemática de estudantes desde os primeiros anos do Ensino Fundamental foram divulgados em Lopes (1998), quando a autora, baseada em currículos internacionais, já defendia a ideia de uma interligação dos estudos de estatística e probabilidade para coletar, organizar e analisar informações diversas, assim como lidar com situações de acaso e incerteza. Essa autora, que se tornou referência na pesquisa sobre o ensino desse campo de conhecimento, esteve sempre atenta para os desafios da incorporação da estatística e da probabilidade em aulas de Matemática, uma vez que apesar de tópicos desses conteúdos há muito constarem nos documentos curriculares em diferentes países, como também no Brasil, eles ainda não eram valorizados.

Em investigação mais recente, em que a pesquisadora analisou a implementação da estatística e probabilidade nas aulas de Matemática do Brasil e dos Estados Unidos, apoiada em Rade (1986 apud LOPES, 2010, p. 47), ela informou que na Conferência de Cambridge, em 1963, já havia sido proposto que a estatística passasse a integrar os conteúdos de Matemática na educação básica, mas que esta proposição não havia logrado êxito. Ela sinalizou também que em sua investigação (realizada mais de duas décadas após o alerta de Rade) encontrara evidências de que

embora a inserção da estatística e da probabilidade seja recomendada nas propostas curriculares de Matemática, na maioria dos países do mundo, ainda não tem sido prioridade na escola, nem nos programas de formação inicial e contínua de professores que ensinam matemática (LOPES, 2010, p. 48).

Assim, mesmo que estudos de probabilidade e estatística sejam cada vez mais considerados social e cientificamente necessários e estejam ganhando maior espaço nos textos oriundos das políticas curriculares brasileiras (BRASIL, 2017), resultados de 
pesquisas, tanto de algum tempo (BIGATÃO JUNIOR, 2004; GOMES, 2006, entre outras) como mais atuais (por exemplo a de PIETROPAOLO; SILVA; CAMPOS, 2015), têm alertado para o fato de que muitos professores e futuros professores do Ensino Fundamental ainda não se apropriaram de conhecimentos para o ensino de noções dessa área ou nem mesmo compreenderam a necessidade de incluir esses temas em suas aulas de Matemática.

Em levantamento diagnóstico realizado por Rodrigues (2014), sobre conhecimentos matemáticos de estudantes ingressantes no curso de Pedagogia de uma instituição federal de ensino superior, futuros professores dos Anos Iniciais, dos noventa e quatro (94) participantes, a maioria deles não soube resolver e explicar questões de combinatória, de probabilidade e de estatística, mesmo tendo estudado esses assuntos na educação básica e terem sido aprovados recentemente no vestibular.

Também investigando futuros professores dos Anos Iniciais do Ensino Fundamental, Gomes (2006) mostrou que o conceito de probabilidade é um dos que tem, por parte de alunas do curso de Pedagogia, maior resistência. Segundo a autora, apesar das discussões promovidas, no intuito de esclarecer que fenômenos aleatórios podem ser explicados matematicamente, as futuras professoras não conseguiram abandonar a ideia de sorte, tão arraigada, parecendo não existirem argumentos suficientes para derrubá-la. No entendimento dessa autora, seria necessário um tempo maior para promover um desequilíbrio da ideia de probabilidade associada à sorte.

Em pesquisa com professores de Matemática dos Anos Finais do Ensino Fundamental que ensinam noções de probabilidade e estatística, Bigatão Junior (2004) destacou que, na maioria das vezes, eles não dominam esses conteúdos sem o auxílio do livro didático ou de algum material pedagógico. Na conclusão de seus estudos o autor se vale da máxima que diz: ninguém ensina o que não sabe.

No caso específico de estudos relativos a noções de probabilidade, Pietropaolo, Silva e Campos (2015) destacaram que muitos docentes não estão sequer convencidos de que esse conteúdo matemático seja importante para ser desenvolvido no ensino médio; quanto ao fundamental, têm uma posição ainda mais restritiva: consideram a inclusão do tema totalmente inadequada e desnecessária. Assim, de acordo com os autores, para promover a inclusão da probabilidade no Ensino Fundamental, seria 
necessário primeiro convencer os professores de que a aprendizagem das noções relativas à probabilidade não é apenas útil para aplicação no cotidiano das pessoas, mas também pelo desenvolvimento de importantes habilidades cognitivas e de formas de pensar.

Em princípio, esses resultados apontam para uma enorme distância existente entre aquilo que é produzido em termos de pesquisa nas universidades e que tem orientado proposições curriculares, e aquilo que é efetivamente incorporado pelos professores nas escolas de educação básica. Fazemos coro aos que, como Lopes e Souza (2016), advertem para o fato de a implementação de inovações curriculares ser muito mais complexa do que recitar prescrições decorrentes de políticas curriculares em cursos para implantação de reformas educacionais. Para os autores, a interpretação e a implementação de uma reforma, por parte dos professores, dependem fortemente da congruência das ideias normativas e do quadro interpretativo pessoal dos docentes, por um lado, e da fundamentação subjacente à reforma, por outro (LOPES; SOUZA, 2016, p. 1467).

E face a essas constatações, como prosseguir? Em que direção apontar? Os professores que ensinam Matemática nos Anos Iniciais têm se apropriado dos fundamentos teóricos subjacentes ao conteúdo das propostas de Matemática a cada reforma curricular? Neste caso, especificamente em relação ao ensino de probabilidade e estatística?

Com a intenção de contribuir com a formação de professores e futuros professores que são ou serão responsáveis pelo ensino de Matemática nos Anos Iniciais do Ensino Fundamental e, mais especificamente, que terão a incumbência de fazer aprender noções de probabilidade e estatística, neste texto trazemos resultados de estudo bibliográfico que apontou para alguns aspectos relativos à fundamentação das justificativas, dos objetivos e das finalidades presentes ou não em documentos curriculares que tratam do ensino de noções de probabilidade e estatística nos Anos Iniciais, bem antes da unidade temática Probabilidade e Estatística assentar-se na atual proposição de uma base nacional comum curricular (BRASIL, 2017).

Temos como hipótese que a explicitação desses fundamentos implicará diretamente na possibilidade de alterar as interpretações curriculares que têm sido, até 
aqui, ainda manifestadas por professores/futuros professores dos Anos Iniciais em relação aos conhecimentos matemáticos não determinísticos como, por exemplo, as noções de acaso e incerteza.

Para isso, tendo em mãos os dois últimos documentos curriculares brasileiros (BRASIL, 1997, 2017), fomos em busca da produção científica no campo da Educação Matemática/Psicologia da Educação Matemática que trata do ensino de noções de probabilidade e estatística, com o foco nos Anos Iniciais do Ensino Fundamental. Essa busca foi realizada no período de 2010 a 2018 em bancos de teses e dissertações; no site da Sociedade Brasileira de Educação Matemática (SBEM), para a consulta de anais de eventos e alguns livros e periódicos disponíveis; em sites de periódicos e revistas para o professor. A partir das referências encontradas em alguns trabalhos, foram também acessados textos disponíveis na internet e em formato impresso.

Nas seções seguintes, trazemos de forma sucinta algumas categorias que emergiram da análise da literatura derivada da produção acadêmica brasileira que, no âmbito dos primeiros anos do Ensino Fundamental, teve como foco as justificativas, os objetivos e as finalidades para a presença de conhecimentos matemáticos não determinísticos nos currículos escolares.

\section{Probabilidade e Estatística: do cálculo à incerteza, algumas demarcações}

A teoria das probabilidades como um ramo da matemática, pode ser compreendida como um modelo matemático do acaso (GARDING, 1997; LAHANIERREUTER, 1998), que estuda fenômenos envolvendo incerteza, utilizando ferramentas básicas do cálculo matemático. "Esses fenômenos, conhecidos como aleatórios ou estocásticos ou não-determinísticos, são aqueles que a sua repetição, em condições idênticas, produz resultados diferenciados, isto é, não é possível determinar, com exatidão, qual o seu resultado" (BAYER et al., 2005, p. 3).

No caso específico da estatística, Lopes (2010, p. 49) afirma que “a estatística, com seus conceitos e métodos para coletar, organizar e analisar informações diversas, tem se revelado um poderoso aliado nesse desafio que é transformar informação bruta em dados que permitem ler a realidade”. De acordo com Pilz (2017, p. 32), 
duas ideias principais no campo da estatística são incerteza e variação. Há muitas situações que encontramos nas ciências e na vida cotidiana nas quais o resultado é incerto. Em muitos casos a incerteza é porque o resultado em questão ainda não foi determinado (por exemplo, nós podemos não saber ainda se vai chover amanhã), enquanto em outros casos a incerteza é porque embora o resultado já tenha sido determinado, nós ainda não fomos informados dele (por exemplo, nós podemos não saber se passamos em um exame específico). A linguagem matemática utilizada para discutir eventos incertos é a probabilidade. Por outro lado, qualquer esforço de medição ou coleta de dados está sujeito a várias fontes de variação. Com isso, queremos dizer que, se a mesma medida for repetida, a resposta provavelmente mudará.

No entendimento de Lopes e Souza (2016, p. 1466), “Probabilidade e Estatística compartilham estudos sobre aleatoriedade e variabilidade em situações cuja ocorrência de eventos não pode ser prevista com certeza absoluta”. De acordo com esses autores, "em estudos estatísticos, a probabilidade dita as regras da análise, de forma que permite determinar um nível de confiança sobre os objetos analisados” (LOPES; SOUZA, 2016, p. 1466).

A explicitação do que trata a área de conhecimento denominada estatística, em especial no que tange ao conhecimento escolar, tem sido aprimorada pelos pesquisadores que, como Lopes (2010), tratam da educação estatística. Entre eles encontram-se Cazorla et al. (2017, p. 14) que apresentam a estatística como

um conjunto de ferramentas para obter, resumir e extrair informações relevantes de dados; encontrar e avaliar padrões mostrados pelos mesmos; planejar levantamentos de dados ou delinear experimentos e comunicar resultados de pesquisas quantitativas. Sua importância reside no auxílio ao processo de pesquisa, que permeia todas as áreas do conhecimento que lidam com observações empíricas.

Em países europeus, América do Norte e Austrália, a integração de combinatória, probabilidade e estatística recebe o nome de estocástica (BOROVCNIK, 2008; TRURAN, 2001), termo que há muito tempo vem sendo utilizado em várias proposições curriculares internacionais. No Brasil, apesar deste termo aparecer em pesquisas, como a de Lopes (1998), nem o termo, nem a integração de combinatória, estatística e probabilidade foram incorporados ao vocabulário curricular nacional.

No que diz respeito especificamente à inclusão de estudos de probabilidade e estatística no currículo, reforçamos aqui o já encontrado por Lopes (1998) quando ao buscar currículos internacionais (espanhol, francês, inglês, italiano, português, japonês e americano) para balizar sua análise de propostas curriculares de alguns estados 
brasileiros que antecederam os Parâmetros Curriculares Nacionais (PCN) de Matemática, pode perceber "que o ensino da estatística e da probabilidade apresentavam-se sempre interligados nos currículos internacionais, tratados por um termo europeu específico, que é estocástica” (LOPES, 1998, p. 10). Encontrou, também, indicadores de que:

o ensino interdisciplinar da estocástica poderá proporcionar aos alunos uma aquisição de conhecimentos menos compartimentalizados, através de experiências que thes permitam fazer observações e tirar conclusões, desenvolvendo, assim, seu pensamento científico, fundamental para sua formação. A metodologia da resolução de problemas torna-se muito recomendada para o trabalho com estocástica, por torná-lo mais significativo. Ao se estabelecer uma questão de investigação, é preciso optar por estratégias que levem a respondê-la. É necessário organizar, representar e analisar os dados a partir do problema. Inseridos nesse processo de aprendizagem, os estudantes provavelmente terão maiores possibilidades de desenvolvimento do pensamento crítico (LOPES, 1998, p. 10).

Ainda que com mais de duas décadas, impressiona a atualidade do texto produzido por Lopes (1998), em especial o capítulo que apresenta as propostas internacionais que há tanto tempo foram produzidas e até mesmo já reformuladas. Particularmente interessante são as atividades pedagógicas apresentadas, que com certeza trariam luz nos dias atuais, ao prescrito nos documentos curriculares oficiais, alargando e muito o que até hoje, ainda não se fez na quase totalidade das aulas de Matemática brasileiras. Também cabe assinalar a vanguarda dos destaques de Lopes (1998) ao realizar uma análise comparativa do que encontrou naqueles currículos, nos seguintes trechos:

percebo a evidência de uma ruptura com o determinismo e a linearidade, predominantes nos currículos de Matemática, justificando, assim, a importância do ensino da Estocástica na Escola Fundamental [...]. Os currículos internacionais estão enfatizando o desenvolvimento da criticidade do aluno ao considerar a importância de se trabalhar com a análise de dados e a necessidade de relacionar o trabalho de Matemática com observações do mundo real. [...] todos os currículos de Matemática dos países citados focalizam a resolução de problemas como foco principal de seu processo ensino-aprendizagem, e pudemos perceber, através de algumas atividades, que o ensino da Estocástica considera essa metodologia como fio condutor de seu desenvolvimento (LOPES, 1998, p. 82-83).

Quanto às observações mais particularizadas a respeito de currículos de países específicos, também apresentadas pela mesma autora, estende-se a cada leitora e 
leitor deste artigo, o convite à leitura da dissertação de Lopes (1998) por marcar o início de uma já extensa trajetória da pesquisa brasileira em Educação Matemática, em Psicologia da Educação Matemática e em Educação Estatística, que toma como objeto de estudo o ensino e a aprendizagem das noções de probabilidade e estatística na escola, área denominada no Programa Internacional de Avaliação de Alunos (PISA) de Incerteza (OECD, 2000).

\section{Da (Não) Aprendizagem ao Ensino: identificando fatores e crenças}

Segundo Godiño, Batanero e Cañizares (1996 apud LOPES, 2010, p. 52), “o ensino tradicional e a perspectiva da ciência em termos de certezas - em que entre o certo e o errado não existe gradação - deram origem a que muitos cidadãos não tenham sido incentivados a lidar com a incerteza e o risco".

0 estudo realizado por Rodrigues (2019), que teve como referência a sua prática docente como formador de futuros professores dos Anos Iniciais do Ensino Fundamental, mostra que muitos estudantes de Pedagogia têm dificuldades com situações de acaso e incerteza. Para muitos deles, acaso e incerteza são termos que, em princípio, parecem não ter nenhuma relação com a matemática, concebida por muitas pessoas como uma ciência pronta e acabada em que não existem espaços para aleatoriedade, para o acaso e para incertezas.

Poderiam essas crenças e concepções manifestadas por estudantes de Pedagogia, em relação a tratamentos matemáticos para situações de acaso e incerteza, influenciar na maneira como irão lidar ao ensinar noções de probabilidade nos Anos Iniciais? No entendimento de Fiorentini (1995), por trás de cada modo de ensinar, esconde-se uma particular concepção de aprendizagem, de ensino, de Matemática e de Educação. Para o autor, o modo de ensinar sofre também influências dos valores e finalidades que o professor atribui ao ensino de Matemática, da forma como concebe a relação professor-aluno e da visão de mundo, de sociedade e de homem (FIORENTINI, 1995).

Em seu estudo, Rodrigues (2019) realizou um sorteio de objetos na tentativa de levantar indicativos de crenças e concepções de estudantes de Pedagogia em relação ao acaso, à aleatoriedade e à incerteza. Ocasião em que alguns estudantes disseram 
não ter sorte porque nunca conseguiram ganhar nada e, por conta disso, se recusaram a participar do sorteio. "Muitas vezes o aluno, acostumado a um pensamento determinístico, tende a aceitar como certa a previsão de um resultado a partir da maior frequência de um evento" (CAZORLA et al., 2017, p. 14).

Nessa situação de sorteio foi possível desafiar os estudantes a pensar sobre a questão da sorte e sobre a questão da chance de ser sorteado. Intuitivamente, sem recorrer a fórmulas de cálculo de probabilidade, eles conseguiram responder quem tinha mais chance de ganhar o "prêmio". Numa turma de Pedagogia, com 40 estudantes, em que a maioria era do sexo feminino, a turma conseguiu justificar o prognóstico probabilístico de que as mulheres teriam mais chance de serem sorteadas, porque havia mais mulheres do que homens na turma. Essa visão intuitiva se constitui numa primeira abordagem de noções de probabilidade nos Anos Iniciais (BATANERO et al., 2016).

Rodrigues (2019) afirma que muitos estudantes de Pedagogia, que participaram de seu estudo, pareceram se preocupar com aspectos práticos voltados para regras, fórmulas e cálculos de probabilidade. Eles queriam saber, por exemplo, como calcular a chance que eles teriam de ganhar na Mega-Sena. Esse contexto de apostas e de jogos, que se fez presente no início do tratamento de situações de acaso pelos humanos, parece permanecer atualmente. 0 interesse que futuros professores têm demonstrado por jogos tem possibilitado a criação de ambientes de aprendizagem em contextos de formação inicial e continuada, em que também se pode assinalar o uso de ferramentas matemáticas para proceder cálculos mentais e escritos que expressem a probabilidade, em situações que envolvam o raciocínio combinatório e o cálculo de proporções, conhecidos há muitos séculos.

Por exemplo, no caso do sorteio realizado em sala de aula do ensino superior, Rodrigues (2019) observou a possibilidade de se estudar equiprobabilidade. Ou seja, aquilo que tem as mesmas chances de ocorrer. Em sua pesquisa, o autor solicitou que cada estudante de Pedagogia escrevesse seu nome em um pedaço de papel com as mesmas dimensões e pediu para que dobrassem os papéis de forma que todos ficassem do mesmo tamanho, impossibilitando que pelo formato pudesse ser identificado previamente algum autor da dobradura. A seguir, solicitou que os depositasse em uma 
urna para realização do sorteio. Com isso, grosso modo, ele criou um espaço amostral equiprovável em que os eventos (papéis dobrados) tiveram as mesmas chances de ocorrência, ou seja, de serem sorteados. Tal situação propiciou uma primeira aproximação sobre equiprobabilidade. Já, o ensino do registro do cálculo de probabilidade por meio de linguagem matemática convencional, pareceu, segundo Rodrigues (2019), ser útil naquela situação para que os participantes da pesquisa relembrassem e verificassem que a medida dessa probabilidade seria a razão entre 0 número de casos favoráveis e o de todos os casos possíveis. $\mathbf{P}(\mathbf{A})=$ total de casos favoráveis / total de casos possíveis.

Entretanto, Rodrigues (2019) alerta que esse enfoque clássico de probabilidade não é suficiente para explicar certos fatos ou fenômenos que ocorrem no âmbito do acaso e da incerteza, mas que não são necessariamente equiprováveis. Por exemplo, nos seus estudos, Rodrigues (2019) perguntou aos mesmos estudantes como eles sabiam que iria chover, eles responderam que sabiam que iria chover quando viam nuvens escuras no céu. E perguntados, há quanto tempo eles fazem esse tipo de observação, responderam que desde crianças. 0 fato de eles perceberem esse fenômeno se repetir com certa frequência, talvez por terem sido alertados pelos mais velhos de que isto iria ocorrer, faz com que eles arrisquem um prognóstico probabilístico se vai chover ou não, a partir das muitas vezes em que em sua vida a observação da existência de nuvens escuras esteve associada a precipitação de chuva. 0 trecho a seguir adverte para o que pode ocorrer com essas previsões.

\footnotetext{
Muitas pessoas, de maneira geral, ao fazer previsões e tomar decisões em situações de incerteza, não utilizam os cálculos de probabilidade ou as teorias estatísticas; ao invés disso, baseiam-se em um número limitado de heurísticas, que, por vezes, podem ajudar razoavelmente, mas, por outras, podem levar a graves erros de interpretação dos fenômenos (MYRVOLD, 2012 apud LOPES; SOUZA, 2016, p. 1475).
}

Batanero (2005) afirma que problemas epistemológicos colocam um papel importante para educadores matemáticos, porque analisam obstáculos que têm historicamente emergido na criação de conceitos e que podem nos ajudar a entender as dificuldades dos estudantes no aprendizado de matemática. Segundo essa autora, isso é particularmente interessante no campo das probabilidades, em que, além de lidar com dificuldades do conhecimento científico, tem-se que lidar com concepções 
equivocadas e crenças a respeito de eventos futuros, estes geralmente atribuídos a deuses ou acarretando outros tipos de explicações.

Mesmo aceitando-se que o acaso tenha sido domesticado pela Matemática por meio da teoria da probabilidade, em diferentes momentos históricos, as intuições que as pessoas, de um modo geral, têm de acaso não são compatíveis com os modelos matemáticos disponíveis (KAHAN, 1996). Nos dias atuais ainda persiste a crença em divindades e nas mais diversas explicações que as pessoas criam ou acreditam. Diante de tais situações os modelos matemáticos de cálculo de probabilidade são considerados em muitas circunstâncias como contra intuitivos, mesmo no meio de pessoas com certo letramento. A literatura derivada das pesquisas em Educação Matemática mostra que a noção de acaso tem sido apontada como uma das mais complexas de se lidar por conta de diferentes interpretações. Daí a importância de sua incorporação às atividades escolares desde a infância.

\section{Intenções Curriculares: da pesquisa ao ensino e vice-versa}

Uma das justificativas para estudos de probabilidade e estatística desde os primeiros anos escolares, conforme já encontrado em propostas curriculares dos estados de Minas Gerais, São Paulo e Santa Catarina, anteriores aos PCN do Ensino Fundamental (BRASIL, 1997) e já analisadas por Lopes (1998); é a possibilidade de uma leitura crítica de mundo com base no tratamento matemático de informações.

Em relação à proposta de São Paulo, Lopes (1998) advertiu que fora tomado para análise apenas o documento "Proposta Curricular para o Ensino de Matemática $1^{\circ}$ grau”, publicado em 1986. 0 fato de não ter analisado outros materiais impressos já existentes na época da coleta de documento, implicou diretamente para que as justificativas curriculares sobre o lugar da Matemática no currículo, ficassem restritas a “ela desenvolver o raciocínio lógico, a capacidade de abstrair, generalizar, projetar, transcender o que é imediatamente sensível”. Assim, ainda que os elaboradores da proposta valorizassem atividades práticas que envolvessem aspectos quantitativos da realidade e inclusive já circulassem materiais impressos contendo atividades nesta direção, o determinismo prevaleceu. 
Lopes (1998) analisou também os Parâmetros Curriculares Nacionais (PCN) de Matemática, especificamente o documento publicado para o primeiro e segundo ciclo e encaminhado aos professores efetivos das escolas públicas brasileiras que ensinavam Matemática de $1^{\mathrm{a}}$ à $4^{\mathrm{a}}$ série do Ensino Fundamental em 1997. Nele constavam algumas noções de estatística, de probabilidade e de combinatória que, justificadas pela crescente importância desses conteúdos em função de seu uso na sociedade, integravam o Bloco de Conteúdos denominado “Tratamento da Informação” (BRASIL, 1997).

Uma justificativa para estudos desses conteúdos na escola era a possibilidade de compreensão de situações de acaso e incerteza por meio de tratamento matemático. A literatura aponta que o homem procura compreender o mundo à sua volta por meio de modelos explicativos e que a questão do acaso e da incerteza perturba o espírito racional. Diante de tal situação, o conhecimento de probabilidade e estatística possibilitaria que muitas explicações de fenômenos aleatórios, dadas única e exclusivamente por meio de nossas crenças em mitos, evoluíssem para um patamar de racionalidade (RODRIGUES, 2011).

Cazorla et al. (2017) entendem que o estudo desses conteúdos na escola propicia o desenvolvimento do pensamento estatístico, a vivência de um trabalho interdisciplinar e possibilita abordar temas transversais. De acordo com os autores, o pensamento estatístico amplia as formas de pensar valorizando o mundo das incertezas. Para eles, como já mencionado neste texto, muitas vezes o aluno, acostumado a um pensamento determinístico, tende a aceitar como certa a previsão de um resultado a partir da maior frequência de um evento (CAZORLA et al., 2017, p. 14).

Em relação às finalidades da abordagem das noções estatísticas $e$ probabilísticas no currículo escolar dos Anos Iniciais, Lopes (1998, p. 98) considerou que:

a proposta não explicita, especificamente, as finalidades do ensino das noções estatísticas e probabilísticas, porém considera que 0 conhecimento socialmente relevante para o aluno é aquele que the permite produzir significados, estabelecer relações, justificar, analisar e criar. Possibilita a leitura, a compreensão e a transformação de sua realidade em sua dimensão física e social. 
Lopes (1998) estabeleceu critérios para a análise dos três currículos estaduais por ela selecionados, sendo um deles "as finalidades da abordagem de tais noções, junto aos estudantes, explicitadas ou não pelas propostas” (LOPES, 1998, p. 8). Da proposta de Minas Gerais ressaltou que:

o indivíduo tem necessidade dessas noções para interpretar inúmeros artigos de jornais e revistas nos quais as informações são dadas sob a forma de porcentagens, de médias, de gráficos, de pictogramas etc. Aponta para o quanto as pessoas são bombardeadas por declarações de políticos, solicitadas por agências de publicidade e sondagens de opiniões; para o delírio do grande público frente aos jogos de azar e o quanto é imprescindível que tenham uma visão realista de suas chances de ganhar e consigam guardar uma atitude crítica diante das 'receitas' para dominar o acaso (LOPES, 1998, p. 92).

Quanto à análise de São Paulo, sobre a finalidade do ensino da estatística e da probabilidade, Lopes (1998) registra que tratava-se de "possibilitar ao aluno entrar em contato e interpretar dados referentes a nossa realidade, pois esse trabalho auxilia a compreensão de outras disciplinas do currículo do $1^{0}$ grau (atual Ensino Fundamental).” (LOPES, 1998, p. 95-96). A estatística aparece no texto da proposta como "um tema de grande aplicação nas demais ciências físicas e sociais e na interpretação de dados de nossa realidade sócio- econômica (LOPES, 1998, p. 96). A probabilidade não é mencionada.

Na proposta curricular de Santa Catarina, publicada em 1997, elaborada com participação ativa dos professores, Lopes (1998) identificou entre os campos de conhecimento, o denominado "Estatística e Probabilidade" e destacou sua abrangência desde a educação infantil até o ensino médio, alguns exemplos disso encontram-se nos seguintes trechos: "o trabalho com leitura, interpretação e construções de tabelas e gráficos que se iniciam também na Educação Infantil de forma não sistematizada até a $3^{a}$ série. A sistematização é proposta a partir da $4^{\text {a }}$ série” (LOPES, 1998, p. 97); e “o trabalho não sistematizado com as probabilidades que se sugere desde o Ensino Infantil até a $7^{\text {a }}$ série" (LOPES, 1998, p. 98).

Em relação às finalidades da abordagem das noções estatísticas $e$ probabilísticas, Lopes (1998, p. 98) considerou que: 
a proposta não explicita, especificamente, as finalidades do ensino das noções estatísticas e probabilísticas, porém considera que 0 conhecimento socialmente relevante para o aluno é aquele que the permite produzir significados, estabelecer relações, justificar, analisar e criar. Possibilita a leitura, a compreensão e a transformação de sua realidade em sua dimensão física e social.

Nos dias atuais, a Base Nacional Comum Curricular (BNCC) explicita que "no que concerne ao estudo de noções de probabilidade, a finalidade, no Ensino Fundamental - Anos Iniciais, é promover a compreensão de que nem todos os fenômenos são determinísticos” (BRASIL, 2017, p. 272). Segundo o documento, “o início da proposta de trabalho com probabilidade está centrado no desenvolvimento da noção de aleatoriedade, de modo que os alunos compreendam que há eventos certos, eventos impossíveis e eventos prováveis” (BRASIL, 2017, p. 272). Quanto a estudos de estatística, espera-se que os alunos compreendam a realidade na qual estão inseridos por meio de uma abordagem matemática que lhes possibilite ler, interpretar, construir gráficos e tabelas para que possam entender as informações ali contidas. Argumentos histórico-socioculturais não são evocados.

\section{Objetivos Curriculares: 0 que já se anunciava antes da BNCC}

Importante assinalar que, nos PCN-Matemática, dentre os "Objetivos de Matemática para o primeiro ciclo" (BRASIL, 1997, p. 65-66), apenas o último abordava noções de Estatística: "Identificar o uso de tabelas e gráficos para facilitar a leitura e interpretação de informações e construir formas pessoais de registro para comunicar informações coletadas. Contudo, nos "Objetivos de Matemática para o segundo ciclo" (BRASIL, 1997, p. 81), três objetivos apresentados abordavam noções de estatística (2) e de probabilidade (1), sendo eles: recolher dados e informações; elaborar formas para organizá-los e expressá-los, interpretar dados apresentados sob a forma de tabelas e gráficos e valorizar essa linguagem como forma de comunicação; utilizar diferentes recursos gráficos - desenhos, esquemas, escritas numéricas - como recurso para expressar ideias, ajudar a descobrir formas de resolução e comunicar estratégias e resultados; e, identificar características de acontecimentos previsíveis ou aleatórios a partir de situações-problema, utilizando recursos estatísticos e probabilísticos. 
Interessante destacar que, apesar dos consultores do PCN-Matemática, César Coll e Délia Lerner Zunino, (BRASIL, 1997, p. 141) estarem familiarizados com o currículo espanhol, dada sua origem, ao analisar o PCN-Matemática, Lopes (1998, p. 112) sinalizou:

Pensamos que os Parâmetros deveriam ter posto em maior evidência as questões relativas ao ensino da probabilidade e da estatística, considerando que tais temas nunca foram antes abordados em propostas curriculares brasileiras, além de não terem feito parte da formação inicial do professor.

Outra observação é quanto ao trabalho com os temas transversais nos quais se considera quase inevitável a utilização da Estocástica. Porém, talvez seja necessário atentar para o cuidado ao envolvê-la em projetos escolares a fim de não a tornarmos um tema desgastado. Isso pode levar nossos estudantes ao desinteresse pela análise de dados, daí a necessidade de serem definidos projetos que promovam um caminhar evolutivo na aquisição dos conceitos estatísticos e probabilísticos.

Cabe relembrar que esses temas já apareciam nas propostas curriculares que antecederam os PCN-Matemática, analisadas por Lopes (1998). A proposta de Minas Gerais, publicada em 1995, fora escolhida por detalhar mais as noções que envolvem incerteza; com o objetivo de: "exercitar um modo de pensar que possibilita lidar com situações não-deterministas em que a incerteza, provocada pelo acaso, encontra-se presente.” (LOPES, 1998, p. 88). A pesquisadora registra também que, na $3^{a}$ série, enfatizava-se a combinatória e, para a $4^{\mathrm{a}}$ série era proposto o trabalho com "acaso", considerado um fenômeno do mundo exterior, sendo sugerido que:

sejam dadas à criança situações de experimentações aleatórias; que se trabalhem os conceitos de universo, de possibilidades e eventos (certo, possível, impossível e possível, mas não certo). Quanto a esse tópico, a proposta faz uma ressalva muito interessante, que é a importância de o aluno ter oportunidade de se familiarizar com tais conceitos, para que ele não adquira uma concepção determinista da Matemática. Propõe, ainda, que se realizem experimentos simples de lançamento de dados ou de moedas, de sorteios de bolas coloridas em um saco opaco e que, em seguida, faça-se a organização em tabelas e a representação por diagramas (pictogramas e diagramas de barra) a fim de se interpretar os resultados coletados nos experimentos (LOPES, 1998, p. 89).

Rodrigues (2011) reuniu objetivos gerais que se pretende alcançar com estudos de probabilidade e estatística em aulas de Matemática junto a estudantes da escola fundamental. Dentre esses objetivos, foram elencados: lidar com a chamada era da informação; tratar matematicamente situações de acaso e incerteza com as quais as 
pessoas convivem diariamente; contemplar os desenvolvimentos da ciência; romper com o determinismo e a linearidade, predominantes nos currículos de Matemática; contribuir para a alteração da imagem social da Matemática que é tida como ciência pronta e acabada; identificar características de acontecimentos previsíveis ou aleatórios a partir de situação-problema; contribuir para o desenvolvimento da capacidade crítica e autonomia do aluno para que exerça plenamente a cidadania; colaborar para a construção de um pensamento não determinístico.

\section{Considerações Finais}

Em defesa de um quadro referencial de fundamentos não determinísticos do conhecimento matemático escolar desde a educação infantil, que possa auxiliar na definição do que seria relevante para ser destacado na formação de professores/futuros professores de Anos Iniciais para o ensino de noções de probabilidade e estatística, o texto aqui apresentado trouxe à luz aspectos relativos às justificativas, objetivos e finalidades que estão na antessala da proposição curricular vigente (BRASIL, 2017). Para isto foram invocadas reconhecidas vozes do campo da Educação Matemática/Psicologia da Educação Matemática e particularmente da Educação Estatística que há muito apontam para:

- a urgência de desenvolver um raciocínio não-determinístico desde a infância;

- a existência de uma zona de confluência nos estudos de probabilidade e estatística em suas relações com a combinatória;

- a necessária interligação do ensino da probabilidade, combinatória e estatística, desde o início da escolaridade.

- a relevância de as noções de chance, aleatoriedade, acaso, incerteza, serem cuidadosamente tratadas nos currículos brasileiros, em todos os níveis escolares.

É necessário reconhecer que algumas tentativas foram realizadas desde o final dos anos 1980, porém, ainda hoje esse campo de conhecimento parece transparente no currículo, uma vez que pouca atenção e tempo tem sido a ele dedicado, particularmente nos Anos Iniciais. Assim, um fértil objeto de pesquisa veio se desenhando no decorrer dos estudos que deram origem a este artigo, trata-se de 
analisar a fundamentação das justificativas, objetivos e finalidades presentes ou não em documentos curriculares e manuais didáticos que tratam do ensino de noções de probabilidade e estatística nos Anos Iniciais, confrontando-os com a atual proposição de uma base nacional comum curricular (BRASIL, 2017), a partir dos conhecimentos acumulados na antessala destes documentos.

Consideramos que a participação colaborativa de estudantes, professores e futuros professores em novos estudos que visem a compreensão dos conteúdos previstos nas orientações curriculares, tendo em vista a reconstrução dos quadros teóricos que fundamentam as nem sempre tão inovadoras proposições curriculares mais recentes será determinante para que possam emergir categorias teórico-práticas que auxiliem a superação das crenças que interferem nas concepções de Matemática que os professores ainda manifestam ao interpretarem itens curriculares envolvendo estudos de probabilidade e estatística. Conhecimentos curriculares que até o momento têm se mostrado de difícil interpretação e implementação em diferentes países.

\section{Referências}

BATANERO, C. Significados de la probabilidad en la educación secundária. Revista latinoamericana de Investigación en Matemática Educativa, México, v. 8, n. 3, p. 247-263, nov. 2005. Disponível em: https://www.relime.org/index.php/numeros/todosnumeros/volumen-9-1/462-volumen-8. Acesso em: 12 ago. 2018.

BATANERO, C.; CHERNOFF, E. J.; ENGEL, J.; LEE, H. S.; SÁNCHEZ, E. Research on teaching and learning probability. Hamburgo: Editora Springer Open, 2016.

BAYER, A.; BITTENCOURT, H.; ROCHA, J.; ECHEVESTE, S. Probabilidade na escola. In: CONGRESSO INTERNACIONAL DE ENSINO DA MATEMÁTICA, 3., 2005, Canoas. Anais [...]. Canoas: SBEM, 2005. p. 1-12. Disponível em:

https://www.researchgate.net/profile/Hr_Bittencourt/publication/265449108_PROBABI LIDADE_NA_ESCOLA/links/5583f75a08ae4738295c401d/PROBABILIDADE-NAESCOLA.pdf. Acesso em: 15 jul. 2017.

BIGATAO JUNIOR, P. A. Concepção do professor de matemática sobre o ensino da estocástica. 2004. Dissertação (Mestrado em Educação Matemática) - Pontifícia Universidade Católica de São Paulo, São Paulo, 2004.

BOROVCNIK, M. Research report of the department of statistics, AAU Klagenfurt. Klagenfurt: University of Klagenfurt, 2017. Disponível em: https://www.aau.at/wpcontent/uploads/2018/04/FOBE_2007_2017_Part I. Acesso em: 18 abr. 2020. 
BOROVCNIK, M. Topic study group 13: research and development in the teaching and learning of probability - aims and focus. [Klagenfurt: University of Klagenfurt], 2008. Disponível em: http://tsg.icme11.org/tsg/show/14. Acesso em: 20 jun. 2008.

BRASIL. Ministério da Educação. Base nacional comum curricular. Brasília: MEC, 2017. Disponível em: http://basenacionalcomum.mec.gov.br/wpcontent/uploads/2018/02/bncc-20dez-site.pdf. Acesso em: 7 jan. 2018.

BRASIL. Ministério da Educação. Diretrizes curriculares para o ensino fundamental de 9 (nove) anos. Brasília: MEC, 2010.

BRASIL. Ministério da Educação. Secretaria de Educação Fundamental. Parâmetros curriculares nacionais. matemática. Brasília: MEC: SEF, 1997.

CAZORLA, I.; MAGINA, S.; GITIRANA, V.; GUIMARÃES, G. (org.). Estatística para os anos iniciais do ensino fundamental. Brasília: Sociedade Brasileira de Educação Matemática, 2017. E-book. Disponível em: http://www.sbem.com.br/files/ebook_sbem.pdf. Acesso em: 22 jun. 2018.

FIORENTINI, D. Alguns modos de ver e conceber o ensino de matemática no Brasil. Zetetiké, Campinas, ano 3, n. 4, p. 1-37, nov. 1995.

GARDING, L. Encontro com a matemática. Tradução de Célia W. Alvarenga, Maria Manuela V. Marques Alvarenga. 2. ed. Brasília: Editora da UnB, 1997.

GODINO, J.; BATANERO, C.; CAÑIZARES, M. J. Azar y probabilidade. Madrid: Editorial Síntesis, 1996.

GOMES, M. G. Obstáculos na aprendizagem matemática: identificação e busca de superação nos cursos de formação de professores das séries iniciais. 2006. Tese (Doutorado em Educação Científica e Tecnológica) - Universidade Federal de Santa Catarina, Florianópolis, 2006.

KAHAN, T. Azar y fisica: Ha cambiado la ciencia de base matemática? In: LIONNAIS, F. (org.). Las grandes corrientes del pensamiento matemático. Buenos Aires: Eudeba, 1996. p.471-487.

LAHANIER-REUTER, D. Etude de conceptions du hasard: approche épistémologique, didactique et expérimentale en milieu universitaire. 1998. Tese (Doutorado em Didática da Matemática) - L'Université de Rennes I, França, 1998.

LOPES, C. A. E. A probabilidade e estatística no ensino fundamental: uma análise curricular. 1998. Dissertação (Mestrado em Educação) - Faculdade de Educação, Universidade Estadual de Campinas, Campinas, 1998.

LOPES, C. E. Os desafios para a educação estatística no currículo de matemática. In: LOPES, C. E.; COUTINHO, C. Q. S.; ALMOULOUD, S. A. (org.). Estudos e reflexões em educação estatística. Campinas: Mercado de Letras, 2010. v. 1, p.47-64. 
LOPES, C. E.; SOUZA, L. O. Aspectos filosóficos, psicológicos e políticos no estudo da probabilidade e da estatística na educação básica. Educação Matemática Pesquisa, São Paulo, v. 18, n. 3, p. 1465-1489, 2016.

OECD - ORGANISATION FOR ECONOMIC COOPERATION AND DEVELOPMENT. Measuring student knowledge and skills. the PISA 2000 assessment of reading, mathematical and scientific literacy. Paris: OECD, 2000. Disponível em: https://www.oecdilibrary.org/docserver/9789264181564en.pdf?expires=1603306744\&id=id\&accname=guest\&checksum=C373B900F3DC98E407 B5CCE7FC9D6671. Acesso em: 20 set. 2020.

OECD - ORGANISATION FOR ECONOMIC COOPERATION AND DEVELOPMENT. PISA 2012 assessment and analytical framework: mathematics, reading, science, problem solving and financial literacy. [Paris]: OECD, 2013. Disponível em: http://dx.doi.org/10.1787/9789264190511-en. Acesso em: 22 jun. 2017.

PEREIRA-MENDOZA, L.; SWIFT, J. Why teach statistics and probability - a rationale. In: SHULTE, A. P.; SMART, J. R. (ed.). Teaching statistics and probability: yearbook 1981. Reston: National Council of Teachers of Mathematics, 1981.

PIETROPAOLO, R. C.; SILVA, A. F. G.; CAMPOS, T. M. M. Conhecimentos necessários ao professor para ensinar noções concernentes à probabilidade nos Anos Finais do Ensino Fundamental. In: CONFERENCIA INTERNACIONAL DE EDUCAÇÃO MATEMATICA, 14., 2015, Chiapas. Anais [...]. Chiapas: CIAEM, 2015. p. 1-10. Disponível em: http://xiv.ciaemredumate.org/index.php/xiv_ciaem/xiv_ciaem/paper/viewFile/1368/700. Acesso em: 20 abr. 2017.

PILZ, J. What is statistics about. In: BOROVCNIK, M. Research report of the department of statistics AAU Klagenfurt. Klagenfurt: University of Klagenfurt, 2017. p. 31-39. Disponivel em: https://www.aau.at/wpcontent/uploads/2018/04/FOBE_2007_2017_Part_I.Acesso em: 18 abr. 2020.

RODRIGUES, J. M. S. A probabilidade como componente curricular na formação matemática inicial de professores polivalentes. 2011. Tese (Doutorado em Educação) Universidade Federal do Paraná, Curitiba, 2011.

RODRIGUES, J. M. S. Conhecimentos matemáticos de alunos de Pedagogia. In: JORNADA NACIONAL DE EDUCAÇÃO MATEMÁTICA, 5.; JORNADA REGIONAL DE EDUCAÇÃO MATEMÁTICA, 18., 2014, Passo Fundo. Anais [...]. Passo Fundo: Universidade de Passo Fundo, 2014. p. 1-15. Disponível em: http://docs.upf.br/download/jem/trabalhos2014/comunicacao-cientifica/conhecimentos_matematicos_de_alunos_pedagogia.pdf. Acesso em: 15 maio 2017.

RODRIGUES, J. M. S. Tratamento da informação na concepção de professoras dos Anos Iniciais e de alunas de Pedagogia em Belém do Pará. In: ENCONTRO NACIONAL DE EDUCAÇÃO MATEMÁTICA, 13., 2019, Cuiabá. Anais [...]. Cuiabá: SBEM, 2019. p. 1-15. Disponível em: https://sbemmatogrosso.com.br/xiiienem/anais.php. Acesso em: 15 set. 2019. 
TRURAN, J. The teaching and learning of probability with special reference to south Australian schools from 1959-1994. 2001. Thesis (Doctor of Philosophy) - Faculty of Arts and Faculty of Mathematical Sciences, University of Adelaide, Australia, 2001.

Recebido em: 22 abr. 2020 Aceite em: 30 jun. 2020 